\title{
A Scoping Review of Intimate Partner Violence Screening Programs for Health Care Professionals
}

\author{
Sheila Sprague ${ }^{1,2 *}$, Gerard P. Slobogean ${ }^{3}$, Hayley Spurr ${ }^{4}$, Paula McKay ${ }^{2}$, Taryn Scott ${ }^{2}$, \\ Erika Arseneau ${ }^{2}$, Muzammil Memon ${ }^{1}$, Mohit Bhandari ${ }^{1,2}$, Aparna Swaminathan $^{5}$ \\ 1 Division of Orthopaedic Surgery, Department of Surgery, McMaster University, Hamilton, Ontario, Canada, \\ 2 Department of Clinical Epidemiology and Biostatistics, McMaster University, Hamilton, Ontario, Canada, \\ 3 Department of Orthopaedics, University of Maryland School of Medicine, Baltimore, Maryland, United \\ States of America, 4 Graduate Entry Medicine, Royal College of Surgeons in Ireland, Dublin, Ireland, \\ 5 Department of Family Medicine, McMaster University, Hamilton, Ontario, Canada \\ * sprags@mcmaster.ca
}

\section{Abstract}

\section{Gopenaccess}

Citation: Sprague S, Slobogean GP, Spurr H, McKay P, Scott T, Arseneau E, et al. (2016) A Scoping Review of Intimate Partner Violence Screening Programs for Health Care Professionals. PLoS ONE 11(12): e0168502. doi:10.1371/journal. pone.0168502

Editor: Saravana Kumar, University of South Australia, AUSTRALIA

Received: July 18, 2016

Accepted: November 30, 2016

Published: December 15, 2016

Copyright: ๑ 2016 Sprague et al. This is an open access article distributed under the terms of the Creative Commons Attribution License, which permits unrestricted use, distribution, and reproduction in any medium, provided the original author and source are credited.

Data Availability Statement: All relevant data are within the paper and its Supporting Information files.

Funding: This study was funded by the Canadian Institutes of Health Research (http://www.cihr-irsc. gc.ca) (KRS - 140988). Funding was received by $\mathrm{SS}, \mathrm{MB}, \mathrm{GS}$, and AS. The funder had no role in study design, data collection and analysis, decision to publish, or preparation of the manuscript.

Competing Interests: The authors have declared that no competing interests exist.

\section{Introduction}

Between 38 and 59 percent of women presenting to health care professionals have experienced intimate partner violence. Consequently, multiple intimate partner violence identification or screening programs within health care settings have been developed; however, substantial variations in program content and interpretation of program effectiveness has resulted in conflicting practice guidelines. The purpose of our scoping review is to broadly identify and synthesize the available literature evaluating intimate partner violence identification programs within health care settings to identify key areas for potential evidence-based recommendations and to focus research priorities in the field.

\section{Materials and Methods}

We conducted a search of MEDLINE, Embase, Cumulative Index of Nursing and Allied Health Literature, Cochrane Database of Systematic Reviews, Cochrane Central Register of Controlled Trials, and psycINFO. We used broad eligibility criteria to identify studies that evaluated intimate partner violence identification programs in health care settings. We completed all screening and data extraction independently and in duplicate. We used descriptive statistics to summarize all data.

\section{Results}

We identified 59 eligible studies evaluating intimate partner violence identification programs within health care settings. The most commonly reported outcome themes were IPV disclosure $(69 \%, n=35)$, number of patients screened $(39 \%, n=20)$, HCP opinions towards screening $(37 \%, n=19)$, and patient opinions towards screening $(29 \%, n=15)$. The majority of studies (36 studies $(70.6 \%)$ ) reported positive program evaluation results. 


\section{Discussion}

The majority of studies reported positive program evaluation results. This may suggest that many different intimate partner violence identification programs are beneficial for identifying victims of abuse, however, it remains unknown as to whether identification programs prevent future episodes of abuse. Additionally, the substantial heterogeneity of the intervention characteristics, study methodology, and outcome measures assessed limits the ability to make clear recommendations as to the optimal method(s) of screening.

\section{Introduction}

Intimate partner violence (IPV), also known as domestic violence, is a violation of human rights that disproportionately affects women. Between 38 and 59 percent of women presenting to health care professionals (HCPs) have experienced IPV [1], and it is estimated that on a global scale, one out of every three women experience IPV at some point in their lives [2]. IPV can escalate to intimate partner homicide, as evidenced by the fact that as many as 38 percent of all murders of women are perpetrated by intimate partners [3]. While women experiencing IPV visit their HCPs more frequently than women not experiencing IPV [4,5], many women are hesitant to disclose IPV, particularly when they are not specifically asked [6].

Taken together, these findings provide a strong rationale for optimizing health care settings to identify victims of IPV and initiate IPV services. Consequently, multiple programs within health care settings have been developed to identify women experiencing IPV; however, substantial variation in program content and effectiveness has created challenges in drawing conclusions [7-9]. Additionally, controversy exists regarding the clinical merits of universal screening [7-13]. Those who support universal screening in health care settings argue that effective screening tools are available [9], screening increases IPV detection rates [14, 15], and the majority of women view screening as acceptable provided that it is conducted in private, sensitive, and non-judgmental manner [16, 17]. Those who do not support universal screening argue that there is insufficient evidence to support implementation $[7,11]$ and that potential adverse outcomes from such programs are unknown [8]. Existing guidelines vary in their recommendations regarding IPV screening and identification practices (e.g. [18-22]). This lack of consensus has resulted in additional research and systematic reviews attempting to provide clear recommendations, however the merits of universal screening and the optimal approach to IPV identification remain contentious. Given the controversies faced and the vast number of studies on the topic, we conducted a scoping review to broadly identify and synthesize the available literature evaluating IPV identification/screening programs within health care settings in order to identify areas for potential evidence-based recommendations and to focus research priorities in the field. Given the breadth and diversity of the existing IPV identification program literature available, a scoping review is the most appropriate methodology to address our research objectives.

\section{Materials and Methods}

Following the scoping review framework proposed by Arksey and O'Malley [23], we used an integrated research process to obtain knowledge user input throughout all six stages of the review's methodology. Knowledge users are defined as those who are "likely to be able to use research results to make informed decisions about health policies, programs and/or practices" 
[24]. A collaboration of physicians, HCPs, researchers, IPV advocates, and IPV victim representatives (see Acknowledgments) made up the knowledge users for our scoping review and directed our research goals and methodology.

\section{Literature Search Strategy}

We consulted with a biomedical librarian to develop a sensitive search strategy to identify all types of publications involving IPV identification, assistance, and educational programs in health care settings within the published literature. Several search strategies and sources were used to identify relevant studies. We used a combination of keywords and medical subject heading $(\mathrm{MeSH})$ terms related to IPV, to search the following electronic databases: MEDLINE, Embase, Cumulative Index of Nursing and Allied Health Literature (CINAHL), Cochrane Database of Systematic Reviews (CDSR), Cochrane Central Register of Controlled Trials (CENTRAL), and psycINFO. All searches were performed in July 2015 and the search was limited to articles published from 2000 and onwards. No language restrictions were employed. Additionally, we conducted a hand search of systematic reviews, meta-analyses, and recently published included studies. A sample of the electronic search strategy is outlined in S1 Table.

\section{Eligibility Criteria}

We included studies in this scoping review if they met the following broad eligibility criteria: (1) published in English; (2) published in full-text format; (3) focused on IPV; (4) evaluated an IPV identification program or IPV screening program for women in a health care setting; (5) level I to IV evidence or used qualitative research methodology; and (6) population comprised of adults. Systematic reviews and meta-analyses were included if they otherwise met our eligibility criteria. We excluded studies that described an IPV screening program but did not evaluate it as well as studies in which an identification program was not the primary intervention (e.g. studies in which IPV assistance or educational programs were the primary intervention evaluated). We also excluded narrative reviews and studies that were published as dissertation abstracts or conference proceedings.

\section{Article Selection}

We reviewed titles of all references identified in the literature search independently and in duplicate (S.B., A.H., K.T., and T.S.). We also reviewed abstracts of all references identified as potentially eligible during title screening independently and in duplicate (E.A., S.B., A.H., M. M., A.S., H.S., S.S., and T.S.). During title screening and abstract screening, reviewers erred on the side of inclusion and included any title that may have potentially met the eligibility criteria. Any conflicts between reviewers about whether or not a title was potentially eligible resulted in inclusion at this stage of the selection process. Two reviewers (S.S. and T.S.) independently and in duplicate reviewed the full-text articles of all references included at the abstract screening level. Any conflicts between the two reviewers were discussed until consensus was reached. All article screening was completed using the web-based program DistillerSR.

\section{Data Extraction}

We completed data extraction for all included studies. Briefly, we extracted data related to study characteristics (e.g. location of research, year of publication, type of journal, etc.), study design characteristics (e.g. study design, number of participants, etc.), screening program characteristics (e.g. form of screening, HCP conducting screening, number of times screening conducted, etc.), methodological characteristics (e.g. use of control group, follow-up, drop-out 
rate, etc.), and its evaluation (i.e. outcome measure themes). Additionally, studies were classified based on program evaluation results as determined by author conclusions (i.e. positive vs. not positive). Two reviewers independently completed the data extraction. Any disagreements in data extraction were resolved by a third reviewer. We completed data extraction in Distiller SR using pre-designed data extraction forms which were piloted to ensure all key information was captured. We provided an instruction manual to each reviewer detailing instructions for data extraction to ensure consistency and accuracy of the extracted data.

\section{Data Analysis}

We used descriptive statistics to summarize all data. For continuous data, we reported the mean and standard deviation or median and interquartile range (IQR) based on the distribution of the data. We used counts and proportions to describe all other data. No inferential statistical testing was performed.

\section{Results}

\section{Article Identification and Selection}

Our search strategy identified a total of 34,814 articles (Fig 1). Of these, 12,644 were duplicates references and were removed prior to our title screening. Therefore, we reviewed 22,170 titles for eligibility and found that 3,277 articles were potentially eligible. Our abstract screening identified 997 potentially eligible abstracts for which we reviewed the full-text. Following the full-text review, we identified 59 articles that met the eligibility criteria and were included in this scoping review [8-10, 12-15, 17, 25-75]. Our hand search of systematic reviews and recently published included studies did not identify any additional eligible studies.

\section{Study Characteristics}

The majority of research was conducted in North America (56\%, $\mathrm{n}=33$ ), Australia/Oceania $(25 \%, \mathrm{n}=15)$ and the United Kingdom $(12 \%, \mathrm{n}=7)$ (Table 1$)$. Only a small proportion of the studies were conducted in Asia ( $5 \%, \mathrm{n}=3)$, Continental Europe ( $5 \%, \mathrm{n}=3)$, and Africa (2\%, $\mathrm{n}=1)$ and no research was conducted in South America. Nearly half $(42 \%, \mathrm{n}=25)$ of all studies were published in medical journals with 19 percent $(n=11)$ published in nursing journals and 15 percent $(n=9)$ in women's health or IPV journals. Less than 25 percent of studies were published in other types of journals. Three-quarters of studies were funded $(75 \%, \mathrm{n}=44)$. Of these 44 studies, government funding was the most frequent $(66 \%, n=29)$ followed by foundation, association, or other non-profit funding $(23 \%, \mathrm{n}=10)$. Twenty percent $(\mathrm{n}=12)$ of studies did not specify if funding was received and five percent $(n=3)$ were unfunded.

\section{Study Design and Methodological Characteristics}

The included studies used a variety of study designs including randomized controlled trials $(19 \%, \mathrm{n}=11)$, qualitative $(\mathrm{n}=8)$, cross-sectional $(\mathrm{n}=8)$, and mixed-method $(\mathrm{n}=8)$ study designs (Table 2). Three-quarters $(n=44)$ of studies reported the number of centres participating in the studies. Of these 44 studies, the majority $(59 \%, n=26)$ were single centre initiatives, 23 percent $(n=10)$ included two to four centres, nine percent $(n=4)$ included five to nine centres, and an additional nine percent $(\mathrm{n}=4)$ included ten or more centres. The median number of participants in the included studies was 302 ( $1^{\text {st }}$ quartile: $126 ; 3^{\text {rd }}$ quartile 1,281 ). The number of participants ranged from 5 [71] to 35,613 [8]. Four studies included more than 10,000 participants and were identified as outliers $[8,10,47,57]$. Three of these studies were 


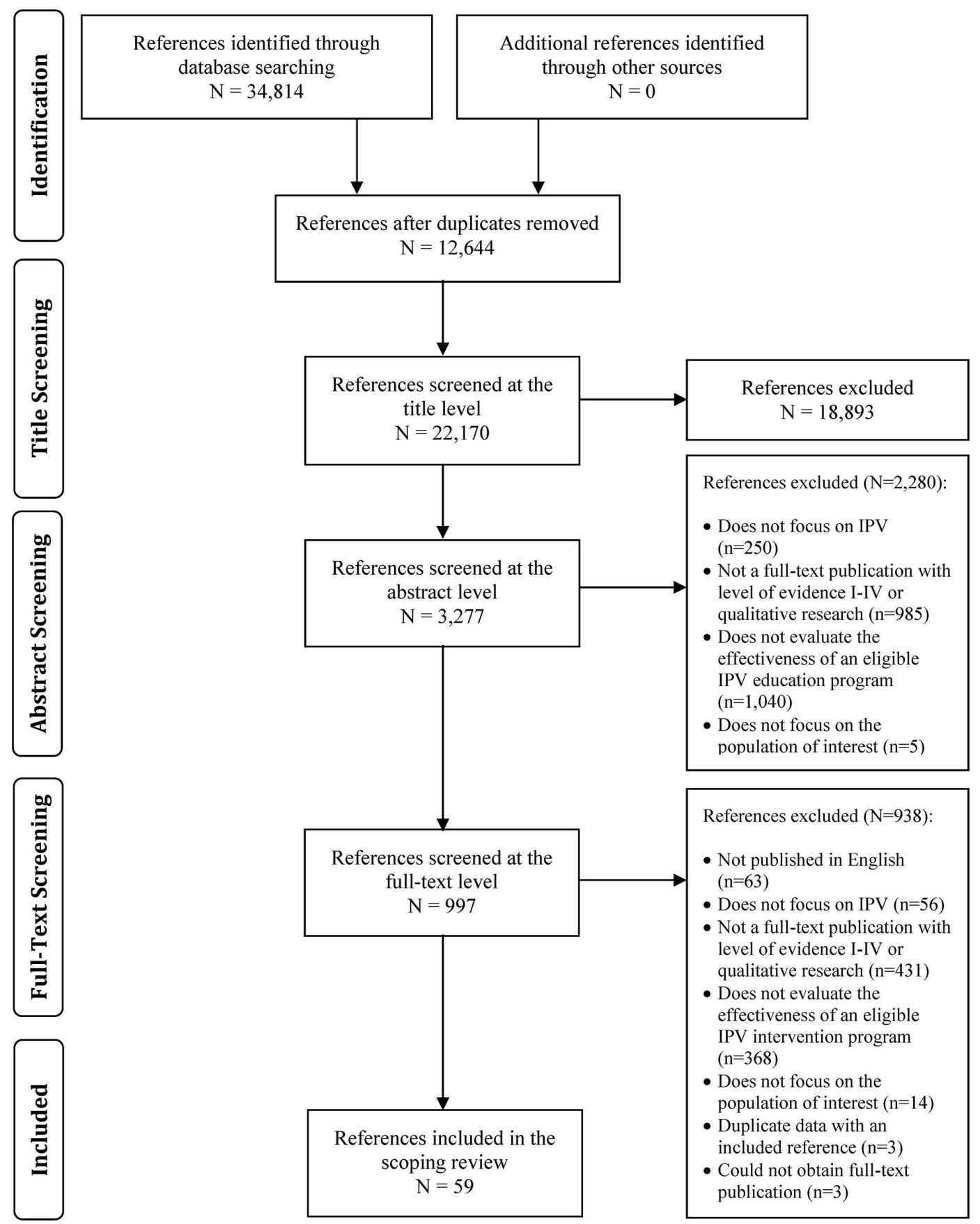

Fig 1. Literature Search Results and Study Selection.

doi:10.1371/journal.pone.0168502.g001

systematic reviews $[8,10,47]$ and one was a case series [57]. When these outliers are removed, the mean number of participants across all included studies was $852.4(\mathrm{SD}=1,451.7)$.

Half of all studies $(\mathrm{n}=26)$ included a control or comparative group and one quarter $(\mathrm{n}=13)$ included a follow-up period. Of the 13 studies that included a follow-up period, 23 percent $(n=3)$ followed participants for up to three months, 31 percent $(n=4)$ followed participants for three to six months, and 23 percent followed participants for more than 6 months. 
Table 1. Study Characteristics.

\begin{tabular}{l|l}
\hline Characteristic & Frequency \\
\cline { 2 - 2 } & $\mathbf{N}(\%) \mathbf{N}=\mathbf{5 9}$ \\
\hline Location of Research* & \\
\hline North America & $33(55.9)$ \\
\hline Australia/Oceania & $15(25.4)$ \\
\hline United Kingdom & $7(11.9)$ \\
\hline Asia & $3(5.1)$ \\
\hline Continental Europe & $3(5.1)$ \\
\hline Africa & $1(1.7)$ \\
\hline Year of Publication & \\
\hline 2000-2004 & $13(22.0)$ \\
\hline 2005-2009 & $25(42.4)$ \\
\hline 2010-2015 & $21(35.6)$ \\
\hline Type of Journal & \\
\hline Medical Journal & $25(42.4)$ \\
\hline Nursing Journal & $11(18.6)$ \\
\hline Women's Health or IPV Journal & $9(15.3)$ \\
\hline Midwifery Journal & $7(11.9)$ \\
\hline Social Science Journal & $5(8.5)$ \\
\hline Health Services/Health Policy Journal & $1(1.7)$ \\
\hline Sexual Health Journal & $1(1.7)$ \\
\hline Study Funding & \\
\hline Funded (n = 44) & \\
\hline Government & $29(65.9)$ \\
\hline Foundation/Association/Non-Profit & $10(22.7)$ \\
\hline Government and Foundation/Association/Non-Profit & $4(9.1)$ \\
\hline Government + Foundation/Association/Non-Profit + Industry/Corporate/Profit & $1(2.3)$ \\
\hline Not Specified & $12(20.3)$ \\
\hline Unfunded & $3(5.1)$ \\
\hline & \\
\hline & \\
\hline & \\
\hline
\end{tabular}

*Numbers do not sum to 59 and percentages do not sum to 100 as some studies were conducted in multiple locations.

doi:10.1371/journal.pone.0168502.t001

Length of follow-up was not clearly reported for an additional 23 percent of studies $(\mathrm{n}=3)$. Additionally, of the 13 studies that reported a follow-up period, 15 percent $(n=2)$ of studies reported a zero percent dropout rate, 46 percent $(n=6)$ reported a dropout rate of less than 30 percent, and 15 percent $(n=2)$ reported a dropout rate greater than 30 percent. The dropout rate for 23 percent $(n=3)$ of studies was not clearly reported.

Studies reported 16 different outcome themes (Table 2). The most commonly reported outcome theme was IPV disclosure which was reported in 69 percent $(n=35)$ of studies. This was followed by number of patients screened $(39 \%, \mathrm{n}=20)$, HCP opinions towards screening $(37 \%, \mathrm{n}=19)$, patient opinions towards screening $(29 \%, \mathrm{n}=15)$, barriers to screening or disclosure $(24 \%, \mathrm{n}=12)$, use of IPV resources $(19.6 \%, \mathrm{n}=10)$, and referral to IPV services ( $16 \%$, $\mathrm{n}=8$ ). The additional nine outcomes themes were reported in less than ten percent of studies. Three different studies $[12,38,40]$ reported outcomes pertaining to improvements in women's lives (i.e. IPV severity/recurrence $(n=3,5.9 \%)$ and health/wellbeing $(n=2,3.4 \%))$. 
Table 2. Study Design and Methodological Characteristics.

\begin{tabular}{|c|c|c|}
\hline \multirow[t]{2}{*}{ Characteristic } & \multirow{2}{*}{$\begin{array}{c}\text { Total } \\
N(\%) N=59\end{array}$} & \multirow[t]{2}{*}{ Reference } \\
\hline & & \\
\hline \multicolumn{3}{|l|}{ Study Design } \\
\hline Randomized Controlled Trial & $11(18.6)$ & $12,13,26,28,30,37,38,39,40,43,52$ \\
\hline Qualitative Study & $8(13.6)$ & $17,35,41,56,59,64,66,73$ \\
\hline Cross-Sectional Study & $8(13.6)$ & $36,54,58,60,61,67,69,75$ \\
\hline Mixed-Methods Study & $8(13.6)$ & $25,27,42,49,50,71,72,74$ \\
\hline Systematic Review & $7(11.9)$ & $8,9,10,14,15,46,51$ \\
\hline Case Series & $6(10.2)$ & $33,34,44,48,53,57$ \\
\hline Pre-Test/Post-Test & $5(8.5)$ & $29,31,63,68,70$ \\
\hline Prospective Comparative Study & $4(6.8)$ & $32,45,55,62$ \\
\hline Meta-Analysis & $1(1.7)$ & 47 \\
\hline Retrospective Comparative Study & $1(1.7)$ & 65 \\
\hline \multicolumn{3}{|l|}{ Number of Centres $(n=44)^{*}$} \\
\hline 1 & $26(59.1)$ & $13,26,27,29,31,32,34,36,37,39,40,42,44,45,48,49,50,53,55,62,68-72,75$ \\
\hline $2-4$ & $10(22.7)$ & $17,28,30,41,52,54,57,60,61,63$ \\
\hline $5-9$ & $4(9.1)$ & $43,59,64,67$ \\
\hline$\geq 10$ & $4(9.1)$ & $12,38,56,58$ \\
\hline \multicolumn{3}{|l|}{ Study Setting $\ddagger$} \\
\hline Obstetrics/Gynecology & $26(44.1)$ & $8-10,12,14,15,17,27,29,36-39,46-49,51,53,56-58,60,61,66,67$ \\
\hline Emergency Department & $21(35.6)$ & $8-10,12,14,32,34,40,41,43,45,46,47,50,51,52,60-62,72,75$ \\
\hline Family Medicine & $15(25.4)$ & $8-10,12-14,17,28,43,46,47,51,64,68,70$ \\
\hline Community Health Centre & $8(13.6)$ & $8,9,12,38,41,46,51,71$ \\
\hline Family Planning Clinic & $5(8.5)$ & $9,38,39,54,63$ \\
\hline Home Visiting Program & $5(8.5)$ & $17,31,33,35,65$ \\
\hline Midwifery & $5(8.5)$ & $25,36,59,73,74$ \\
\hline Pediatrics & $5(8.5)$ & $10,14,26,46,57$ \\
\hline Mental Health & $4(6.8)$ & $46,56-58$ \\
\hline Internal Medicine & $2(3.4)$ & 14,55 \\
\hline Sexual Health Clinic & $2(3.4)$ & 44,46 \\
\hline Women's Health Clinic & $2(3.4)$ & 30,43 \\
\hline Abortion Clinic & $1(1.7)$ & 69 \\
\hline Outpatient Hospital Department & $1(1.7)$ & 42 \\
\hline \multicolumn{2}{|c|}{ Number of Participants (median $\left(1^{\text {st }} \mathrm{Q}, 3^{\text {rd }} \mathrm{Q}\right)$ ) } & $302(126,1281)$ \\
\hline \multicolumn{3}{|c|}{ Use of Control/Comparative Group(n= 51)† } \\
\hline Yes & $26(51.0)$ & $12,13,25-32,37-40,43,45,52,55,60,62,63,65,68,70,72,74$ \\
\hline \multicolumn{3}{|c|}{ Inclusion of a Follow-Up Period $(n=51) \dagger$} \\
\hline Yes & $13(25.5)$ & $12,17,27,29,31,33,37-40,63,68,74$ \\
\hline \multicolumn{3}{|c|}{ Length of Follow-up (months) $(n=13)$} \\
\hline$<0$ to $\geq 3$ & $3(23.1)$ & $27,39,40$ \\
\hline$<3$ to $\geq 6$ & $4(30.8)$ & $33,37,63,74$ \\
\hline$<6$ & $3(23.1)$ & $12,38,68$ \\
\hline Not Reported & $3(23.1)$ & $17,29,31$ \\
\hline \multicolumn{3}{|l|}{ Dropout Rate $(n=13)$} \\
\hline 0 & $2(15.4)$ & 29,68 \\
\hline 1 to 30 & $6(46.2)$ & $37-40,63,74$ \\
\hline$>30$ & $2(15.4)$ & 12,27 \\
\hline Not Reported & $3(23.1)$ & $17,31,33$ \\
\hline
\end{tabular}

(Continued) 
Table 2. (Continued)

\begin{tabular}{l|l|l}
\hline \multirow{2}{*}{ Characteristic } & \multicolumn{1}{|c|}{ Total } & \multirow{2}{*}{ Reference } \\
\cline { 2 - 2 } Outcome Themes $(\mathbf{n}=\mathbf{5 1})$ & $\mathbf{N}(\%) \mathbf{N}=\mathbf{5 9}$ & \\
\hline IPV Disclosure & $35(68.6)$ & $12,13,26-28,30-34,36,37,39,41-45,48-50,52-54,57,58,60-62,65,68,69,71,74,75$ \\
\hline Screening & $20(39.2)$ & $25,29,36,44,48-50,53-55,57,59,62,63,65,69-71,74,75$ \\
\hline HCP Opinions Towards Screening & $19(37.3)$ & $13,17,28,35,36,42,44,49,50,54,56,59,61,63,66,71-74$ \\
\hline Patient Opinions Towards Screening & $15(29.4)$ & $13,17,26-28,36,37,39,41,43,50,58,64,67,71$ \\
\hline Barriers to Screening/Disclosure & $12(23.5)$ & $25,35,49,50,56,59,64,69,71,73-75$ \\
\hline Use of IPV Resources & $10(19.6)$ & $12,17,36,38,39-41,62,63,75$ \\
\hline Referral to IPV Services & $8(15.7)$ & $13,33,50,52,62,63,72,75$ \\
\hline IPV Discussions with HCP & $5(9.8)$ & $13,17,50,52,63$ \\
\hline Chart Documentation of IPV & $4(7.8)$ & $13,49,63,65$ \\
\hline IPV Severity/Recurrence & $3(5.9)$ & $12,38,40$ \\
\hline Screening Form Completion & $3(5.9)$ & $43,54,60$ \\
\hline Screening Harm Measures & $3(5.9)$ & $12,41,58$ \\
\hline Substance Use/Abuse & $3(5.9)$ & $12,13,37$ \\
\hline Health/Wellbeing & $2(3.4)$ & 12,38 \\
\hline Economic/Efficiency & $2(3.4)$ & 17,28 \\
\hline Safety & $2(3.4)$ & 13,40 \\
\hline Other & $5(9.8)$ & $25,38,42,58,75$ \\
\hline
\end{tabular}

* Number of centres was either not applicable or not reported for 15 studies.

¥Numbers do not sum to 59 and percentages do not sum to 100 as some studies reported multiple characteristics.

†Data not abstracted for 7 systematic review and 1 meta-analysis studies.

doi:10.1371/journal.pone.0168502.t002

\section{Intervention Characteristics}

Identification interventions took place in 14 different health care settings. The most frequent setting was obstetrics and gynecology $(44 \%, \mathrm{n}=26)$, followed by emergency medicine (36\%, $\mathrm{n}=21)$, family medicine $(25 \%, \mathrm{n}=15)$, and community health centres $(14 \%, \mathrm{n}=8)$. Three quarters $(\mathrm{n}=38)$ of studies evaluated IPV identification programs that involved in-person screening (Table 3$)$. Fourteen percent $(n=7)$ examined computer-based screening, ten percent $(n=5)$ paper-based, and two percent $(n=1)$ audio/visual based. In-person identification interventions were performed by a variety of different HCPs and study personnel. Nurses were the most common group $(45 \%, \mathrm{n}=17)$ followed by midwives $(24 \%, \mathrm{n}=9)$, social workers, counsellors, or IPV coordinators $(13 \%, n=5)$, and physicians or surgeons $(11 \%, n=4)$. Other HCPs and study personnel conducted screening in less than six percent of studies. Eighty percent $(n=41)$ of studies specified that HCPs were provided with some sort of IPV identification training. Approximately three quarters of the studies specified the number of times women were screened with the majority $(63 \%, \mathrm{n}=32)$ being screened once.

Three-quarters of studies used a questionnaire for IPV identification. Thirty percent $(n=15)$ of studies developed their own questionnaire for the study while 26 percent $(n=13)$ adapted an existing questionnaire and 20 percent $(n=10)$ used an existing questionnaire. Of the ten studies that used an existing questionnaire, the most commonly used questionnaires were the Partner Violence Screen (PVS) $(40 \%, \mathrm{n}=4)$ and the Women Abuse Screening Tool (WAST) $(40 \%, n=4)$. Two-thirds of studies $(\mathrm{n}=33)$ specified that some sort of assistance was provided to women who screened positive for IPV. The types of assistance provided included 
Table 3. Intervention Characteristics.

\begin{tabular}{|c|c|c|}
\hline \multirow[t]{2}{*}{ Characteristic } & \multirow{2}{*}{$\begin{array}{c}\text { Total } \\
\mathrm{N}(\%) \mathrm{N}=51^{*}\end{array}$} & \multirow[t]{2}{*}{ Reference } \\
\hline & & \\
\hline \multicolumn{3}{|l|}{ IPV Identification Intervention } \\
\hline In-person & $38(74.5)$ & $17,25,29-36,40-42,44,45,48-50,53-59,61,63-67,69-75$ \\
\hline Computer & $7(13.7)$ & $13,27,38,39,43,52,62$ \\
\hline Paper & $5(9.8)$ & $12,28,37,60,68$ \\
\hline Audio/video & $1(2.0)$ & 26 \\
\hline \multicolumn{3}{|l|}{ HCP who Performed Screening $(n=38)$} \\
\hline Nurse & $17(44.7)$ & $31,33,35,40-42,49,50,53-55,61,63,65,66,72,75$ \\
\hline Midwife & $9(23.7)$ & $17,25,36,40,59,61,67,73,74$ \\
\hline Social Worker/Counsellor/IPV coordinator & $5(13.2)$ & $33,34,40,53,69$ \\
\hline Physician/Surgeon & $4(10.5)$ & $42,50,53,70$ \\
\hline Study Personnel & $3(7.9)$ & $17,30,45$ \\
\hline Other Allied HCPs & $3(7.9)$ & $33,42,71$ \\
\hline Resident & $1(2.6)$ & 29 \\
\hline Not Specified & $7(18.4)$ & $32,44,48,56-58,64$ \\
\hline \multicolumn{3}{|l|}{ Identification Training Provided to HCPs } \\
\hline Yes & $41(80.4)$ & $12,13,17,25,26,28-31,33,35-38,40-44,48-50,53,54,56-63,65,67-72,74,75$ \\
\hline No & $3(5.9)$ & $27,52,73$ \\
\hline Not Specified & $7(13.7)$ & $32,34,39,45,55,64,66$ \\
\hline \multicolumn{3}{|l|}{ Number of Times Women Were Screened } \\
\hline Once & $32(62.7)$ & $12,13,26-28,30-32,34-36,38,45,50,52,53,56,58,60-62,67-70,72$ \\
\hline Three times & $4(7.8)$ & $17,29,37,59$ \\
\hline Every three months & $1(2.0)$ & 49 \\
\hline Not specified & $14(27.5)$ & $25,33,48,54,55,57,63-66,71,73-75$ \\
\hline \multicolumn{3}{|l|}{ Questionnaire Used for Identification† } \\
\hline Yes & $37(72.5)$ & $12,13,17,26-28,30,32,33,36-45,49,50,52,54,56-62,64,65,67-69,71,72$ \\
\hline No & $14(27.5)$ & $25,29,31,34,35,48,53,55,63,66,70,73-75$ \\
\hline \multicolumn{3}{|l|}{ Questionnaire Used $(n=10) \dagger$} \\
\hline Partner Violence Screen & $4(40.0)$ & $32,38,39,43$ \\
\hline Woman Abuse Screening Tool & $4(40.0)$ & $12,28,43,60$ \\
\hline Hurt, Insult, Threaten, And Scream & $2(20.0)$ & 28,64 \\
\hline Composite Abuse Scale & $1(10.0)$ & 43 \\
\hline Conflict Tactics Scale & $1(10.0)$ & 30 \\
\hline Violence Against Women Screen & $1(10.0)$ & 37 \\
\hline \multicolumn{3}{|c|}{ Assistance Provided to Women Experiencing IPV } \\
\hline Yes & $33(64.7)$ & $12,13,17,26,28,30,33,34,36-45,48-50,54-59,62-64,71,72,75$ \\
\hline Not Specified & $18(35.3)$ & $25,27,29,31,32,35,52,53,60,61,65-70,73,74$ \\
\hline \multicolumn{3}{|l|}{ Type of Assistance $(n=33) \dagger$} \\
\hline IPV Resources & $28(84.8)$ & $12,13,17,26,28,30,33,34,36-39,41,43-45,50,54-59,62,64,71,72,75$ \\
\hline Referral & $18(54.5)$ & $13,33,34,36,37,40-42,45,49,50,54,56,58,62,63,71,72$ \\
\hline Counselling/Advocacy & $14(42.4)$ & $13,17,33,34,37-39,42,45,48,50,55,63,72$ \\
\hline Safety Planning & $8(24.2)$ & $13,33,34,37,40,41,62,63$ \\
\hline Home Visitation & $2(6.1)$ & 17,33 \\
\hline
\end{tabular}

*Data not abstracted for 7 systematic review and 1 meta-analysis studies.

†Percentages do not sum to 100 as some studies reported multiple intervention characteristics.

doi:10.1371/journal.pone.0168502.t003 
provision of IPV resources $(85 \%, \mathrm{n}=28)$, referral $(55 \%, \mathrm{n}=18)$, counselling/advocacy $(42 \%$, $\mathrm{n}=14)$, safety planning $(24 \%, \mathrm{n}=8)$, and home visitations $(6 \%, \mathrm{n}=2)$.

\section{Studies Reporting Positive Program Evaluation Results}

Our scoping review identified 36 studies (70.6\%) that reported positive program evaluation results, 10 studies (19.6\%) that reported neutral or mixed results, 4 studies $(7.8 \%)$ where the results were not concluded, and 1 study (2.0\%) where the results were negative. We looked at outcome themes by stratifying all studies by program evaluation (i.e. positive versus not positive). Outcome themes amongst studies frequently reporting positive results (i.e. positive results reported for $\geq 75 \%$ of studies in which at least 5 studies include the specified program characteristic) included those that looked at outcomes pertaining to screening ( $80.0 \%$ of studies reported a positive program evaluation) and IPV disclosure (77.1\% of studies reported a positive program evaluation) (Table 4). Of the three studies that reported outcomes assessing improvements in women's lives (i.e. IPV severity/recurrence and health/wellbeing), all three reported neutral program evaluation results. Of the 48 studies that did not report outcomes assessing improvements in women's lives, 36 (75.0\%) reported positive program evaluation results, 7 (14.6\%) reported neutral or mixed results, 4 (8.3\%) did not specify program evaluation conclusions, and 1 (2.1\%) reported negative results.

\section{Discussion}

This scoping review represents a comprehensive overview of the published literature on IPV identification programs and IPV screening programs within health care settings. Our review included 59 studies evaluating different IPV identification programs within health care

Table 4. Outcome Theme by Program Evaluation Results.

\begin{tabular}{|c|c|c|c|}
\hline \multirow[t]{4}{*}{ Outcome Theme } & \multirow[t]{2}{*}{ Total } & \multicolumn{2}{|c|}{ Frequency } \\
\hline & & \multicolumn{2}{|c|}{ Total\% } \\
\hline & $N(\%) N=51 *$ & Positive N(\%) & Not Positive N(\%) \\
\hline & & $N=36(70.6 \%)$ & $\mathrm{N}=15(29.4 \%)$ \\
\hline IPV Disclosure & $35(68.6)$ & $27(77.1)$ & $8(22.9)$ \\
\hline Screening & $20(39.2)$ & $16(80.0)$ & $4(20.0)$ \\
\hline HCP Opinions Towards Screening & $19(37.3)$ & $11(57.9)$ & $8(42.1)$ \\
\hline Patient Opinions Towards Screening & $15(29.4)$ & $11(73.3)$ & $4(26.7)$ \\
\hline Barriers to Screening/Disclosure & $12(23.5)$ & $7(58.3)$ & $5(41.7)$ \\
\hline Use of IPV Resources & $10(19.6)$ & $6(60.0)$ & $4(40.0)$ \\
\hline Referral to IPV Services & $8(15.7)$ & $6(75.0)$ & $2(25.0)$ \\
\hline IPV Discussions with $\mathrm{HCP}$ & $5(9.8)$ & $2(40.0)$ & $3(60.0)$ \\
\hline Chart Documentation of IPV & $4(7.8)$ & $3(75.0)$ & $1(25.0)$ \\
\hline IPV Severity/Recurrence & $3(5.9)$ & $0(0.0)$ & $3(100.0)$ \\
\hline Screening Form Completion & $3(5.9)$ & $2(66.7)$ & $1(33.3)$ \\
\hline Screening Harm Measures & $3(5.9)$ & $2(66.7)$ & $1(33.3)$ \\
\hline Substance Use/Abuse & $3(5.9)$ & $2(66.7)$ & 1 (33.3) \\
\hline Health/Wellbeing & $2(3.4)$ & $0(0.00)$ & $2(100.0)$ \\
\hline Economic/Efficiency & $2(3.4)$ & $0(0.0)$ & $2(100.0)$ \\
\hline Safety & $2(3.4)$ & $1(50.0)$ & $1(50.0)$ \\
\hline Other & $5(9.8)$ & $4(80.0)$ & $1(20.0)$ \\
\hline
\end{tabular}

*Data not abstracted for 7 systematic review and 1 meta-analysis studies.

doi:10.1371/journal.pone.0168502.t004 
settings. The majority of this research was conducted in North America (56\%) and Australia/ Oceania (25\%). Only a small proportion of the studies were conducted in Asia, Continental Europe, and Africa and no research was conducted in South America. This may represent differing attitudes towards IPV and IPV identification within health care settings internationally. IPV identification studies were published in a variety of different journals indicating an interest in IPV identification research across multiple health care disciplines.

A wide variety of study designs were used within the IPV identification literature with randomized controlled trials being the most common design (19\%) followed by qualitative, crosssectional, and mixed methods studies (14\% each). The frequent use of qualitative and mixed methods study designs likely reflects the importance of rich data describing patient and $\mathrm{HCP}$ insight into IPV identification. For example, qualitative and mixed methods studies have focused on understanding women's perceptions and experiences with undergoing IPV screening $[17,27,41]$ as well as HCPs' experiences, perceptions, and comfort with conducting screening $[49,56,59,66]$.

Only one-quarter of all studies, and $45 \%$ of all RCTs, included a follow-up period. The limited number of studies that chose to include a follow-up period is likely explained by the type of outcomes measured. For example, outcomes such as screening rate, IPV disclosure rate, patient opinions towards screening (which were three of the four most commonly reported outcomes) do not require follow-up periods. Conversely, other outcomes such as use of IPV resources, health and wellbeing, or IPV severity or recurrence require follow-up periods to assess changes in outcomes, however these outcomes were assessed less frequently. Coster [76] emphasizes the importance of ensuring that study follow-up times are selected so that they are long enough to allow for changes to be seen in the construct being measured, and for measurement instruments to detect the changes. Therefore, the heterogeneity in outcome measures within the included studies may partially explain the variation in the inclusion of a follow-up period and follow-up period duration.

Interventions took place in a number of different health care settings indicating an interest and need for IPV identification programs across multiple settings. While programs included substantial heterogeneity, the majority of studies reported positive results for IPV screening programs ( $71 \%$ of studies). This suggests that the most important factor may be that women are being asked about IPV in some manner, and the details about how they are asked are less important.

Over 16 different outcome themes were identified across the included studies. The most common outcome themes focused on determining whether screening took place (e.g. screening rate), whether women disclosed the occurrence of IPV (e.g. disclosure rate), and patients' and HCPs' feelings towards the identification program. Studies that included screening and IPV disclosure outcomes themes frequently reported positive program evaluation results (80.0\% and $77.1 \%$ respectively). While these outcomes are important in order to assess if the identification program is feasible (i.e. ability to implement the program and have it accepted by women and HCPs) and accomplishing the primary goal of identifying women who are experiencing IPV, they are not able to assess whether or not women were actually helped. Three different RCTs included in our scoping review did assess these types of outcomes which included: IPV severity or recurrence ( 3 studies) and health and wellbeing (2 studies). The programs being evaluated in these studies included varying forms of assistance for women including IPV resource lists, statements about the unacceptability of violence, risk assessment, and referral. Of the three studies that assessed IPV severity and recurrence, two $[38,40]$ reported no significant differences between participants in the IPV identification group and the control group and one reported small differences in favour of the IPV identification group [12]. 
Neither of the two studies that assessed health and wellbeing outcomes reported differences between the IPV identification group and control group [12, 38].

These same three studies $[12,38,40]$ all three reported neutral program evaluation results. This is in contrast to the 48 studies that did not include outcomes assessing improvements in women's lives, which reported positive program evaluation results 75 percent of the time $(\mathrm{n}=36)$. Although the sample size is small, these findings suggest that conclusions regarding program evaluation may be influenced by the outcomes selected. For example, given the complex and multifaceted nature of IPV, it is unlikely that identification programs alone (i.e. those that are not also coupled with assistance and educational programs) will result in reductions in the severity/recurrence of IPV or improvements in health/wellbeing outcomes. This is because the purpose of identification program is simply to determine which women are experiencing IPV and consequently, their ability to lead to improvement women's circumstances is dependent on the provision of effective assistance interventions by qualified HCPs. Future research should focus on assessing patient important outcomes in IPV programs that include all screening, assistance, and educational components with particular attention paid to the impact of outcome selection on result interpretation.

This scoping review has several strengths that contribute to its quality. A research librarian with expertise in the area designed and conducted the search strategy to ensure all published literature was captured. Additionally, all article screening was completed in duplicate by reviewers with both content and methodological expertise. Finally, to the best of our knowledge this scoping review is the first to assess IPV identification programs.

Despite these strengths, our scoping review is limited by the restriction of our search to published literature. This may introduce publication bias into our results as it is possible that there are a higher proportion of studies with neutral or negative results that are unpublished compared to positive ones. Our scoping review was also limited to studies published in English which may partially explain the limited number of studies found that were conducted in Asia, Continental Europe, South America, and Africa. Additionally, the heterogeneity of study design and interventions introduced challenges of capturing all of the details of each included study. However, by focusing our scoping review on the commonalities between studies we were able to produce a comprehensive summary of the existing literature.

\section{Conclusions}

Overall, the results of the current scoping review provide a comprehensive summary of the existing literature in the field of IPV identification programs within health care settings. The majority of studies included in this scoping review reported positive program evaluation results. This may suggest that many different IPV identification programs are beneficial, particularly in regards to identifying victims of abuse; however, it remains unknown as to whether identification programs prevent future episodes of abuse. Additionally, the substantial heterogeneity of the intervention characteristics, study methodology, and outcome measures assessed limits the ability to make clear recommendations as to the optimal method(s) of screening.

\section{Supporting Information}

S1 Database. Minimal Data Set.

(XLSX)

S1 Table. Search Strategy (e.g. MEDLINE).

(DOCX) 
S2 Table. PRISMA Checklist.

(DOCX)

\section{Acknowledgments}

The authors would like to acknowledge the following individuals for their contributions to this scoping review:

Knowledge Users: Gina Agarwal, Jason Busse, Ari Collerman, Vanina Dal Bello-Haas, Samir Faidi, David Florkowski, Clare Freeman, Nisha Gupta, Norma MacIntyre, Brad Petrisor, Angela Reitsma, Emil Schemitsch, Doug Thomson, Diana Tikasz, Milena Vicente, Andrew Worster

Administrative Support: Sofia Bzovsky, Alisha Garibaldi, Kim Madden, Lucshman Raveendran, Kerry Tai

Literature Search Support: Neera Bhatnagar

Statistical Support: Lehana Thabane

\section{Author Contributions}

Conceptualization: SS GS PM MB.

Formal analysis: SS TS.

Funding acquisition: SS GS MB AS.

Investigation: SS AS HS EA MM TS.

Methodology: SS GS PM MB.

Project administration: SS TS.

Supervision: SS GS MB.

Visualization: SS PM TS.

Writing - original draft: SS PM TS.

Writing - review \& editing: SS GS HS PM TS EA MM MB AS.

\section{References}

1. Sprague S, Goslings JC, Hogentoren C, de Milliano S, Simunovic N, Madden K, et al. Prevalence of intimate partner violence across medical and surgical health care settings: a systematic review. Violence Against Women. 2014; 20:118-36. doi: 10.1177/1077801213520574 PMID: 24476759

2. World Health Organization. Violence against women: Intimate partner and sexual violence against women. 2016. Available: http://www.who.int/mediacentre/factsheets/fs239/en/. Accessed 11 July 2016.

3. World Health Organization. Global and regional estimates of violence against women: Prevalence and health effects of intimate partner violence and non-partner sexual violence. 2013. Retrieved from http:// apps.who.int/iris/bitstream/10665/85239/1/9789241564625_eng.pdf. Accessed 30 June 2016.

4. Gass JD, Stein DJ, Williams DR, Seedat S. Intimate partner violence, health behaviours, and chronic physical illness among South African women. S Afr Med J. 2010 Sep 7; 100(9):582-5. PMID: 20822646

5. Rivara FP, Anderson ML, Fishman P, Bonomi AE, Reid RJ, Carrell D, et al. Healthcare utilization and costs for women with a history of intimate partner violence. Am J Prev Med. 2007 Feb; 32(2):89-96. doi: 10.1016/j.amepre.2006.10.001 PMID: 17234483

6. Morse DS, Lafleur R, Fogarty CT, Mittal M, Cerulli C. "They told me to leave": how health care providers address intimate partner violence. J Am Board Fam Med. 2012 May-Jun; 25(3):333-42. doi: 10.3122/ jabfm.2012.03.110193 PMID: 22570397

7. O'Doherty L, Hegarty K, Ramsay J, Davidson LL, Feder G, Taft A. Screening women for intimate partner violence in healthcare settings. Cochrane Database Syst Rev. 2015; 7:1-103. 
8. Ramsay J, Richardson J, Carter YH, Davidson LL, Feder G. Should health professionals screen women for domestic violence? Systematic review. BMJ. 2002; 325:1-13.

9. Kataoka Y, Yaju Y, Eto H, Matsumoto N, Horiuchi S. Screening of domestic violence against women in the perinatal setting: a systematic review. Japan Journal of Nursing Science 2004; 1:77-86.

10. Nelson HD, Bougatsos $C$, Blazina I. Screening women for intimate partner violence: a systematic review to update the U.S. Preventive Services Task Force recommendation. Ann Intern Med. 2012; 156:796808. doi: 10.7326/0003-4819-156-11-201206050-00447 PMID: 22565034

11. Moyer VA; U.S. Preventive Services Task Force. Screening for intimate partner violence and abuse of elderly and vulnerable adults: U.S. preventive services task force recommendation statement. Ann Intern Med. 2013 Mar 19; 158:478-86. doi: 10.7326/0003-4819-158-6-201303190-00588 PMID: 23338828

12. MacMillan HL, Wathen $C N$, Jamieson $E$, Boyle MH, Shannon HS, Ford-Gilboe M, et al. Screening for intimate partner violence in health care settings: a randomized trial. JAMA. 2009; 302:493-501. doi: 10. 1001/jama.2009.1089 PMID: 19654384

13. Ahmad F, Hogg-Johnson S, Stewart DE, Skinner HA, Glazier RH, Levinson W. Computer-assisted screening for intimate partner violence and control: a randomized trial. Ann Intern Med. 2009; 151: 93102. PMID: 19487706

14. Trabold N. Screening for intimate partner violence within a health care setting: A systematic review of the literature. Soc Work Health Care. 2007; 45:1-18.

15. O'Reilly R, Beale B, Gillies D. Screening and intervention for domestic violence during pregnancy care: a systematic review. Trauma Violence Abuse. 2010; 11:190-201. doi: 10.1177/1524838010378298 PMID: 20688785

16. Feder GS, Hutson M, Ramsay J, Taket AR. Women exposed to intimate partner violence: expectations and experiences when they encounter health care professionals: a meta-analysis of qualitative studies. Arch Intern Med. 2006; 166:22-37. doi: 10.1001/archinte.166.1.22 PMID: 16401807

17. Bacchus L, Mezey G, Bewley S. Women's perceptions and experiences of routine enquiry for domestic violence in a maternity service. BJOG. 2002; 109:9-16. PMID: 11843378

18. The American College of Obstetricians and Gynecologists. Intimate partner violence. Committee Opinions. 2012. Available: http://www.acog.org/Resources-And-Publications/Committee-Opinions/ Committee-on-Health-Care-for-Underserved-Women/Intimate-Partner-Violence. Accessed 06 July 2016.

19. Cherniak D, Grant L, Mason R, Moore B, Pellizzari R; IPV Working Group. Society of Obstetricians and Gynaecologists of Canada. Intimate partner violence consensus statement. J Obstet Gynaecol Can. 2005; 27:365-418. PMID: 15999433

20. Canadian Orthopaedic Association. Intimate Partner Violence position statement by the Canadian Orthopaedic Association. 2009. Available: http://www.coa-aco.org/images/stories/library/health_policy/ IPV_Statement.pdf. Accessed 06 July 2016.

21. National Institute for Health and Care Excellence. Domestic violence and abuse: multi-agency working. 2014. Available: https://www.nice.org.uk/guidance/ph50/chapter/4-considerations\#identifyingdomestic-violence-or-abuse. Accessed 18 Oct 2016.

22. World Health Organization. Responding to intimate partner violence and sexual violence against women WHO clinical and policy guidelines. 2013. Retrieved from: http://apps. who.int/iris/bitstream/ 10665/85240/1/9789241548595_eng.pdf?ua=1. Accessed 18 Oct 2016.

23. Arksey H, O'malley L. Scoping studies: towards a methodological framework. Int J Soc Res Methodol 2005; 8:19-32.

24. Canadian Institutes of Health Research. Guide to knowledge translation planning at CIHR: Integrated and end-of-grant approaches. In: Knowledge translation and commercialization. 2015. Available: http:// www.cihr-irsc.gc.ca/e/45321.html. Accessed 18 January 2015.

25. Baird K, Salmon D, White P. A five year follow-up study of the Bristol pregnancy domestic violence programme to promote routine enquiry. Midwifery. 2013; 29:1003-1010. doi: 10.1016/j.midw.2013.01.007 PMID: 23455032

26. Bair-Merritt MH, Feudtner C, Mollen CJ, Winters S, Blackstone M, Fein JA. Screening for intimate partner violence using an audiotape questionnaire: a randomized clinical trial in a pediatric emergency department. Arch Pediatr Adolesc Med. 2006; 160:311-316. doi: 10.1001/archpedi.160.3.311 PMID: 16520452

27. Chang JC, Dado D, Schussler S, Hawker L, Holland CL, Burke JG, et al. In person versus computer screening for intimate partner violence among pregnant patients. Patient Educ Couns. 2012; 88:443448. doi: 10.1016/j.pec.2012.06.021 PMID: 22770815 
28. Chen PH, Rovi S, Washington J, Jacobs A, Vega M, Pan KY, et al. Randomized comparison of 3 methods to screen for domestic violence in family practice. Ann Fam Med. 2007; 5:430-435. doi: 10.1370/ afm.716 PMID: 17893385

29. Duncan MM, Mclntosh PA, Stayton CD, Hall CB. Individualized performance feedback to increase prenatal domestic violence screening. Matern Child Health J. 2006; 10:443-449. doi: 10.1007/s10995006-0076-0 PMID: 16710766

30. Fincher D, VanderEnde K, Colbert K, Houry D, Smith LS, Yount KM. Effect of face-to-face interview versus computer-assisted self-interview on disclosure of intimate partner violence among African American women in WIC clinics. J Interpers Violence. 2015; 30:818-838. doi: 10.1177/0886260514536280 PMID: 24923890

31. Grafton D, Wright BL, Gutmanis I, Ralyea S. Successful implementation of universal woman abuse inquiry. Public Health Nurs. 2006; 23:535-540. doi: 10.1111/j.1525-1446.2006.00593.x PMID: 17096779

32. Halpern LR, Parry BA, Hayward G, Peak D, Dodson TB. A comparison of 2 protocols to detect intimate partner violence. J Oral Maxillofac Surg. 2009; 67:1453-1459. doi: 10.1016/j.joms.2009.03.003 PMID: 19531417

33. Hawkins JW, Pearce CW, Skeith J, Dimitruk B, Roche R. Using technology to expedite screening and intervention for domestic abuse and neglect. Public Health Nurs. 2009; 26:58-69. doi: 10.1111/j.15251446.2008.00754.x PMID: 19154193

34. Hugl-Wajek JA, Cairo D, Shah S, McCreary B. Detection of domestic violence by a domestic violence advocate in the ED. J Emerg Med. 2012; 43:860-865. doi: 10.1016/j.jemermed.2009.07.031 PMID: 19782496

35. Jack SM, Jamieson E, Wathen CN, MacMillan HL. The feasibility of screening for intimate partner violence during postpartum home visits. Can J Nurs Res. 2008; 40:150-170. PMID: 18714904

36. Jones C, Bonner M. Screening for domestic violence in an antenatal clinic. Aust J Midwifery. 2002; 15:14-20. PMID: 12017039

37. Kataoka $\mathrm{Y}$, Yaju $\mathrm{Y}$, Eto $\mathrm{H}$, Horiuchi S. Self-administered questionnaire versus interview as a screening method for intimate partner violence in the prenatal setting in Japan: a randomised controlled trial. BMC Pregnancy Childbirth. 2010; 10:84. doi: 10.1186/1471-2393-10-84 PMID: 21182802

38. Klevens J, Kee R, Trick W, Garcia D, Angulo FR, Jones R, et al. Effect of screening for partner violence on women's quality of life: a randomized controlled trial. JAMA. 2012; 308:681-689. doi: 10.1001/jama. 2012.6434 PMID: 22893165

39. Klevens J, Sadowski L, Kee R, Trick W, Garcia D. Comparison of screening and referral strategies for exposure to partner violence. Womens Health Issues. 2012; 22:e45-e52. doi: 10.1016/j.whi.2011.06. 008 PMID: 21798763

40. Koziol-McLain J, Garrett N, Fanslow J, Hassall I, Dobbs T, Henare-Toka TA, et al. A randomized controlled trial of a brief emergency department intimate partner violence screening intervention. Ann Emerg Med. 2010; 56:413-423.e1. doi: 10.1016/j.annemergmed.2010.05.001 PMID: 20538369

41. Koziol-McLain J, Giddings L, Rameka M, Fyfe E. Intimate partner violence screening and brief intervention: experiences of women in two New Zealand Health Care Settings. J Midwifery Womens Health. 2008; 53:504-510. doi: 10.1016/j.jmwh.2008.06.002 PMID: 18984506

42. Laisser RM, Nyström L, Lindmark G, Lugina HI, Emmelin M. Screening of women for intimate partner violence: a pilot intervention at an outpatient department in Tanzania. Glob Health Action. 2011; 4:7288. doi: 10.3402/gha.v4i0.7288 PMID: 22028679

43. MacMillan HL, Wathen CN, Jamieson E, Boyle M, McNutt LA, Worster A, et al. Approaches to screening for intimate partner violence in health care settings: a randomized trial. JAMA. 2006; 296:530-536. doi: 10.1001/jama.296.5.530 PMID: 16882959

44. McNulty A, Andrews $\mathrm{P}$, Bonner $\mathrm{M}$. Can screening for domestic violence be introduced successfully in a sexual health clinic? Sex Health. 2006; 3:179-182. PMID: 17044223

45. Morrison LJ, Allan R, Grunfeld A. Improving the emergency department detection rate of domestic violence using direct questioning. J Emerg Med. 2000; 19:117-124. PMID: 10903457

46. O'Campo P, Kirst M, Tsamis C, Chambers C, Ahmad F. Implementing successful intimate partner violence screening programs in health care settings: evidence generated from a realist-informed systematic review. Soc Sci Med. 2011; 72:855-866. doi: 10.1016/j.socscimed.2010.12.019 PMID: 21330026

47. O'Doherty LJ, Taft A, Hegarty K, Ramsay J, Davidson LL, Feder G. Screening women for intimate partner violence in healthcare settings: abridged Cochrane systematic review and meta-analysis. BMJ. 2014; 348:g2913. doi: 10.1136/bmj.g2913 PMID: 24821132 
48. Onifade R, Von Rege I, Mumford S, Bewley S. Achieving continuous improvement in routine questioning about domestic violence with an embedded advocacy service. J Obstet Gynaecol. 2010; 30:550552. doi: 10.3109/01443615.2010.494208 PMID: 20701499

49. Owen-Smith A, Hathaway J, Roche M, Gioiella ME, Whall-Strojwas D, Silverman J. Screening for domestic violence in an oncology clinic: barriers and potential solutions. Oncol Nurs Forum. 2008; 35:625-633. doi: 10.1188/08.ONF.625-633 PMID: 18591166

50. Ramsden C, Bonner M. A realistic view of domestic violence screening in an emergency department. Accid Emerg Nurs. 2002; 10:31-39. PMID: 11998582

51. Renker PR. Breaking the barriers: the promise of computer-assisted screening for intimate partner violence. J Midwifery Womens Health. 2008; 53:496-503. doi: 10.1016/j.jmwh.2008.07.017 PMID: 18984505

52. Rhodes KV, Drum M, Anliker E, Frankel RM, Howes DS, Levinson W. Lowering the threshold for discussions of domestic violence: a randomized controlled trial of computer screening. Arch Intern Med. 2006; 166:1107-1114. doi: 10.1001/archinte.166.10.1107 PMID: 16717173

53. Scholle SH, Buranosky R, Hanusa BH, Ranieri L, Dowd K, Valappil B. Routine screening for intimate partner violence in an obstetrics and gynecology clinic. Am J Public Health. 2003; 93:1070-1072. PMID: 12835182

54. Shattuck SR. A Domestic Violence Screening Program in a public health department. J Community Health Nurs. 2002; 19:121-132. doi: 10.1207/S15327655JCHN1903_01 PMID: 12378890

55. Soglin LF, Bauchat J, Soglin DF, Martin GJ. Detection of intimate partner violence in a general medicine practice. J Interpers Violence. 2009; 24:338-348. doi: 10.1177/0886260508316481 PMID: 18667690

56. Spangaro J, Poulos RG, Zwi AB. Pandora doesn't live here anymore: normalization of screening for intimate partner violence in Australian antenatal, mental health, and substance abuse services. Violence Vict. 2011; 26:130-144. PMID: 21776834

57. Spangaro JM. The NSW Health routine screening for domestic violence program. N S W Public Health Bull. 2007; 18:86-89. PMID: 17651662

58. Spangaro JM, Zwi AB, Poulos RG, Man WY. Six months after routine screening for intimate partner violence: attitude change, useful and adverse effects. Women Health. 2010; 50:125-143. doi: 10.1080/ 03630241003705060 PMID: 20437301

59. Stenson K, Sidenvall B, Heimer G. Midwives' experiences of routine antenatal questioning relating to men's violence against women. Midwifery. 2005; 21:311-321. doi: 10.1016/j.midw.2005.01.002 PMID: 16061312

60. Svavarsdottir EK. Detecting intimate partner abuse within clinical settings: self-report or an interview. Scand J Caring Sci. 2010; 24:224-232. doi: 10.1111/j.1471-6712.2009.00709.x PMID: 20230520

61. Svavarsdottir EK, Orlygsdottir B. Identifying abuse among women: use of clinical guidelines by nurses and midwives. J Adv Nurs. 2009; 65:779-788. doi: 10.1111/j.1365-2648.2008.04872.x PMID: 19183236

62. Trautman DE, McCarthy ML, Miller N, Campbell JC, Kelen GD. Intimate partner violence and emergency department screening: computerized screening versus usual care. Ann Emerg Med. 2007; 49:526-534. doi: 10.1016/j.annemergmed.2006.11.022 PMID: 17276547

63. Ulbrich PM, Stockdale J. Making family planning clinics an empowerment zone for rural battered women. Women Health. 2002; 35:83-100.

64. Usta J, Antoun J, Ambuel B, Khawaja M. Involving the health care system in domestic violence: what women want. Ann Fam Med. 2012; 10:213-220. doi: 10.1370/afm.1336 PMID: 22585885

65. Vanderburg S, Wright L, Boston S, Zimmerman G. Maternal child home visiting program improves nursing practice for screening of woman abuse. Public Health Nurs. 2010; 27:347-352. doi: 10.1111/j.15251446.2010.00865.x PMID: 20626835

66. Webster F, Bouck MS, Wright BL, Dietrich P. Nursing the social wound: public health nurses' experiences of screening for woman abuse. Can J Nurs Res. 2006; 38:136-153. PMID: 17290959

67. Webster J, Stratigos SM, Grimes KM. Women's responses to screening for domestic violence in a health-care setting. Midwifery. 2001; 17:289-294. doi: 10.1054/midw.2001.0279 PMID: 11749061

68. Wenzel JD, Monson CL, Johnson SM. Domestic violence: prevalence and detection in a family medicine residency clinic. J Am Osteopath Assoc. 2004; 104:233-239. PMID: 15233329

69. Wiebe ER, Janssen P. Universal screening for domestic violence in abortion. Womens Health Issues. 2001; 11:436-441. PMID: 11566286

70. Hamberger LK, Guse CE, Patel D, Griffin E. Increasing physician inquiry for intimate partner violence in a family medicine setting: Placing a screening prompt on the patient record. J Aggress Maltreat Trauma. 2010; 19:839-852. 
71. Howard J. Domestic violence screening: Findings of a pilot project conducted by allied health staff in community health. Aust J Prim Health. 2008; 14:43-51.

72. Power C, Bahnisch L, McCarthy D. Social work in the emergency department-Implementation of a domestic and family violence screening program. Australian Social Work. 2011; 64:537-554.

73. McCosker-Howard H, Kain V, Anderson DJ, Webster J. The impact on midwives of undertaking screening for domestic violence: Focus group findings. Birth Issues. 2005; 14:49-56.

74. Price S, Baird K, Salmon D. Does routine antenatal enquiry lead to an increased rate of disclosure of domestic abuse? Findings from the Bristol Pregnancy and Domestic Violence Programme. Evidence Based Midwifery. 2007; 5:100-106.

75. Ramsden C, Bonner M. An early identification and intervention model for domestic violence. Australian Emergency Nursing Journal. 2002; 5:15-20.

76. Coster WJ. Making the best match: selecting outcome measures for clinical trials and outcome studies. Am J Occup Ther. 2013; 67:162-70 doi: 10.5014/ajot.2013.006015 PMID: 23433270 